\title{
Links of the significant wave height distribution in the Mediterranean sea with the Northern Hemisphere teleconnection patterns
}

\author{
P. Lionello and M. B. Galati \\ University of Salento, Dept. of Material Sciences, Via per Monteroni, km 1.2, Plesso M, Lecce, Italy \\ Received: 31 December 2007 - Revised: 12 March 2008 - Accepted: 15 May 2008 - Published: 20 June 2008
}

\begin{abstract}
This study analyzes the link between the SWH (Significant Wave Height) distribution in the Mediterranean Sea during the second half of the 20th century and the Northern Hemisphere SLP (Sea Level Pressure) teleconnection patterns.

The SWH distribution is computed using the WAM (WAve Model) forced by the surface wind fields provided by the ERA-40 reanalysis for the period 1958-2001. The time series of mid-latitude teleconnection patterns are downloaded from the NOAA web site. This study shows that several midlatitude patterns are linked to the SWH field in the Mediterranean, especially in its western part during the cold season: East Atlantic Pattern (EA), Scandinavian Pattern (SCA), North Atlantic Oscillation (NAO), East Atlantic/West Russia Pattern (EA/WR) and East Pacific/ North Pacific Pattern (EP/NP). Though the East Atlantic pattern exerts the largest influence, it is not sufficient to characterize the dominant variability. NAO, though relevant, has an effect smaller than EA and comparable to other patterns. Some link results from possibly spurious structures. Patterns which have a very different global structure are associated to similar spatial features of the wave variability in the Mediterranean Sea. These two problems are, admittedly, shortcomings of this analysis, which shows the complexity of the response of the Mediterranean SWH to global scale SLP teleconnection patterns.
\end{abstract}

\section{Introduction}

Teleconnection (TLC) patterns have been proposed to describe monthly variability of SLP fields at global scale (Barnston and Livezey, 1987). They are the result of a statistical procedure meant to identify the dominant mode

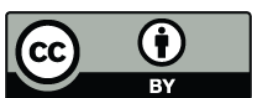

Correspondence to: P. Lionello piero.lionello@unile.it of monthly variability. Technically, the procedure involves rotated EOFs and some subjective evaluation for identifying each pattern in the set produced by the analysis of single calendar months. Each month, in fact, produces different patterns and the identification of TLC is based on permanent characteristic features, which persist in spite of the change of the shape of the rotated EOFs. The identification of the TLC patterns is based on global scale features, so that at regional scale, when the Mediterranean region is considered, the same pattern can present different aspects in different months. An example, discussed in the next chapter, is the structure of EP/NP above the Mediterranean region, which greatly varies during the annual cycle. An index describing its intensity is associated to each mid-latitude TLC pattern. The values used in this study have been downloaded from the NOAA web page at http://www.cpc.ncep.noaa.gov/data/teledoc/telecontents.shtml.

No wave observation is available to cover a period as long as the ERA-40, not even at few and sparse locations. Regular wave gauges became operational in few stations in the late 80 s and satellite observations are available only since early 90s. The monthly average wave data used in this analysis have been extracted from a model simulation ( $\mathrm{Li}-$ onello and Sanna , 2005) done with the WAM (WAve Model, WAMDI 1987) forced by the surface wind fields provided by the ERA-40 (Simmons and Gibson, 2000) reanalysis for the period 1958-2001. It has, however, been shown that the inter-monthly variability is well reproduced by this simulation (Lionello and Sanna, 2005). This analysis considers the monthly mean SWH (Significant Wave Height), a vector whose length is proportional to the variance of the sea surface, which points to the mean direction of propagation of the total wave energy.

The purpose of this study is to identify TLC patterns associated with the wave variability in the Mediterranean, as described in the following Sect. 2, and to discuss the importance of these links (Sect. 3, conclusions).

Published by Copernicus Publications on behalf of the European Geosciences Union. 

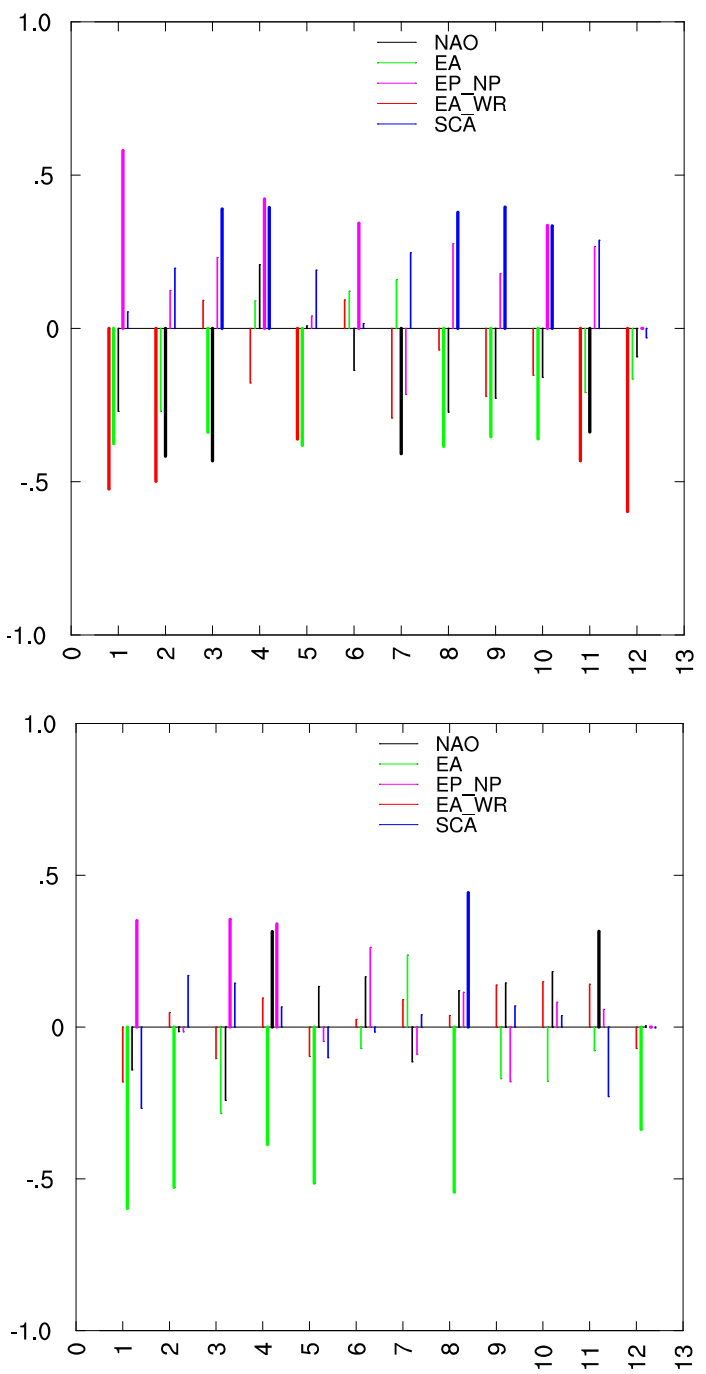

Fig. 1. Annual cycle (calendar months on the $\mathrm{x}$-axis) of the correlation between monthly average SWH field and teleconnection pattern indexes. Only NAO, EA, EP/NP, EA/WR, SCA are shown. Other patterns have smaller and less relevant correlation values. Thick bars denote value significant at the $95 \%$ confidence level. The two panels refer to the western (top) and eastern (bottom) part of the Mediterranean.

\section{Teleconnections and waves in the Mediterranean sea}

A preliminary analysis has shown that the link between TLC patterns and SWH is not uniform across the Mediterranean basin. This can be expected, just considering the different characteristics of its various sub-basins, the complex shape of the Mediterranean and its transitional nature from midlatitude to subtropical climate regimes (Lionello et al 2006).

A first computation has been carried out by splitting the Mediterranean in two parts: north-west south-east, with the Otranto and the Sicily straits marking the division line between the two parts so that the Ionian sea belongs to the south-east part. For each part the monthly average SWH and its correlation with the TLC patterns have been computed.

This first analysis shows a clear difference between northwest and south-east Mediterranean (Fig. 1). While the second one is affected mainly by EA, with only marginal influence of EP/NP, NAO, and SCA, the first one is strongly influenced by several patterns and, beside EA, SCA, during spring and fall, also EA/WR, during the cold season, play a relevant role. This shows that NAO, though being important, cannot be considered the dominant TLC for the Mediterranean SWH.

Specifically, EA is the most dominant pattern, with negative correlation during most of the year in both basins. SCA has a positive correlation with the north-west part during spring and fall, EA/WR has a negative correlation during the cold season in the west (November to February), NAO has a well defined negative correlation for the west, during several month, and a positive correlation in the east, however only for November and April. Surprisingly EP/NP results a relevant pattern for both the parts of the Mediterranean (this result will be discussed later in the paper).

The following analysis concentrates on January when the simultaneous influence of many TLC patterns is present (except for SCA, for which April is considered).

\section{$2.1 \quad$ EA}

EA positive phase is characterized by a strong negative pressure anomaly in the north-eastern Atlantic, which moves to the center of the basin from December to March. Its effect in the Mediterranean depends little by the location of the main Atlantic minimum and mostly by that of a high pressure system over the basin itself, often shifted towards its eastern part. During the EA positive phase the overall effect of the high pressure is a diminished north-westerly circulation, so that positive EA implies lower than average SWH, particularly in the eastern Mediterranean (Fig. 2). The effect of EA is present for the whole year, but it is particularly strong from January to March, and absent in June and July.

\section{$2.2 \mathrm{EA} / \mathrm{WR}$}

This pattern has a strong link with west Mediterranean SWH from November to February, when it is characterized by a high pressure located over most of central Europe and framed between two pressure centers, over West Russia and the mid-Atlantic. This SLP pattern implies a large reduction of the north-westerly circulation in the western Mediterranean, with a reduction of the SWH of the corresponding wave systems travelling across the basin (Fig. 3).

\subsection{SCA}

This pattern is characterized by a high pressure above Scandinavia. However, its effect in the Mediterranean monthly wave field is determined by the position of the low pressure 


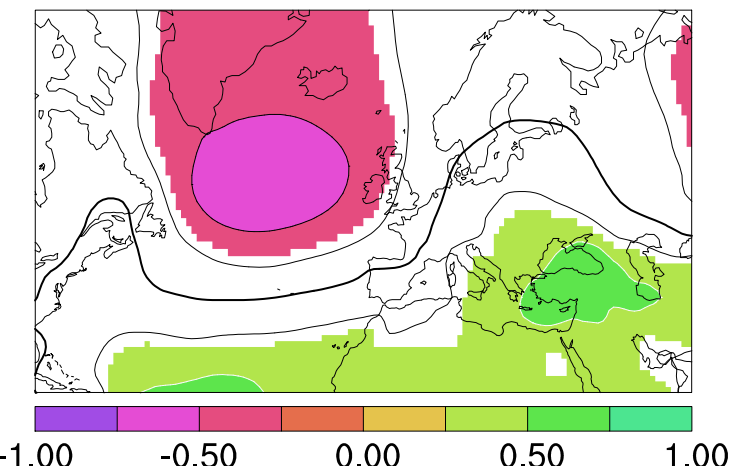

(a)
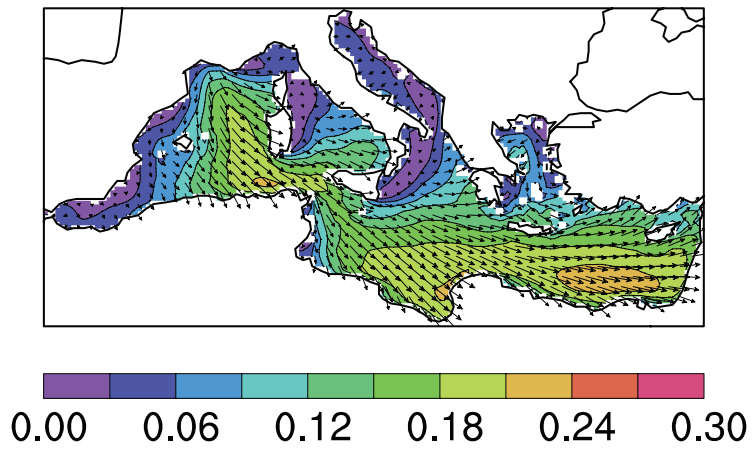

(c)
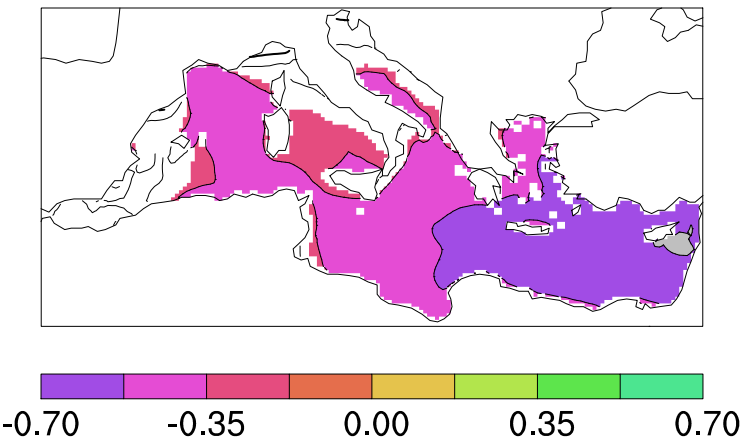

(b)
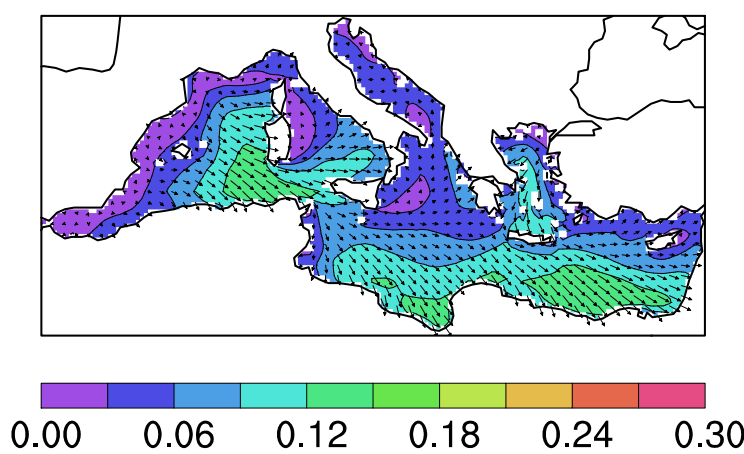

(d)

Fig. 2. January: correlation of EA index with SLP and SWH, (a) and (b) panel, respectively. In the colour filled areas the correlation is significant at the 95\% confidence level. Panels (c) and (d) show the composites of SWH (meters) during months with the 9 most high and low values of the EA index, respectively.

south-west of it, across western Europe and north west Atlantic. When it is located northwest of the basin, it produces a south-westerly surface circulation in the west Mediterranean, which favours wave travelling towards north-east. Consequently SCA has a positive correlation with the SWH in the Mediterranean. This effect is large during spring (Fig. 4 describes the situation in April) and autumn.

\subsection{NAO}

NAO is a well known mode of the mid-latitude variability and is characterized by a pressure dipole across the Atlantic. It is the extension of the Azores high pressure system which is important for the Mediterranean wave field. In its most familiar condition, the presence of high pressure in the western Mediterranean corresponds to a situation of reduced westerly surface flows and reduced SWH in the northern part of the basin (e.g. January, Fig. 5). In November, when the high pressure field extends until the Black Sea, its local curvature increases the southward propagating waves in the eastern Mediterranean.

\section{$2.5 \mathrm{EP} / \mathrm{NP}$}

EP/NP is characterized by center of actions located in the Pacific. It is therefore puzzling that it is relevant for the Mediterranean, and, moreover, in January, while the pattern is strongest during the warm season. This is possibly a spurious attribution and it shows a shortcoming of the TLC identification approach. In January, what is classified as EP/NP pattern shows a large and highly significant (statistically) feature centered in the Mediterranean. This low pressure produces a strong regional circulation and consequently is associated to an increase of SWH (Fig. 6). A similar regional effect on SWH, but due to a completely different SLP pattern, is produced in April, when EP/NP present a high pressure located south-west of the Mediterranean basin.

\section{Conclusions}

When discussing TLCs, it should be considered that they are the result of a statistical analysis and not of a well known dynamics. In this study they are used for analyzing links between regional features (the monthly SWH in the Mediterranean) and the large scale SLP field. 


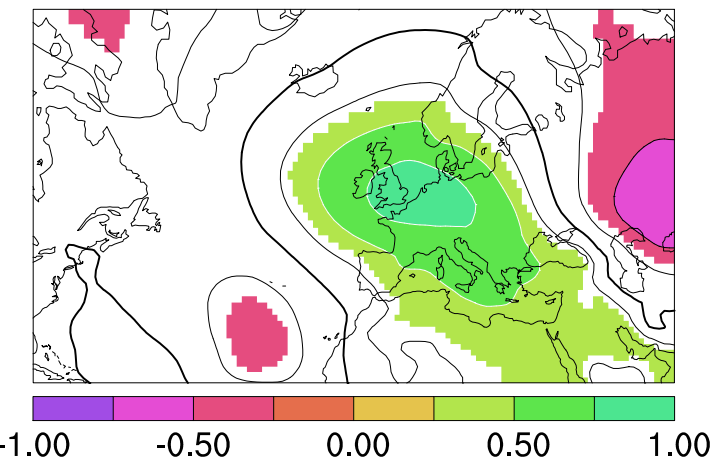

(a)
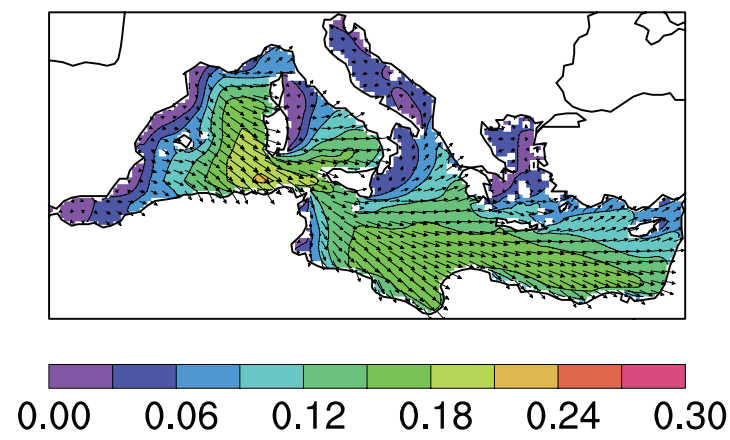

(c)
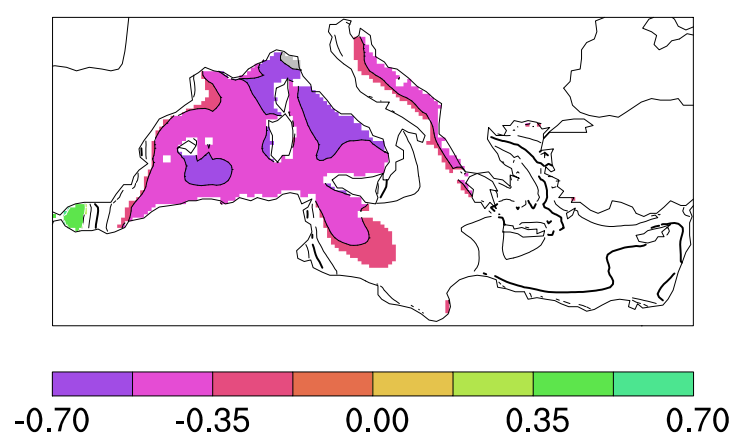

(b)
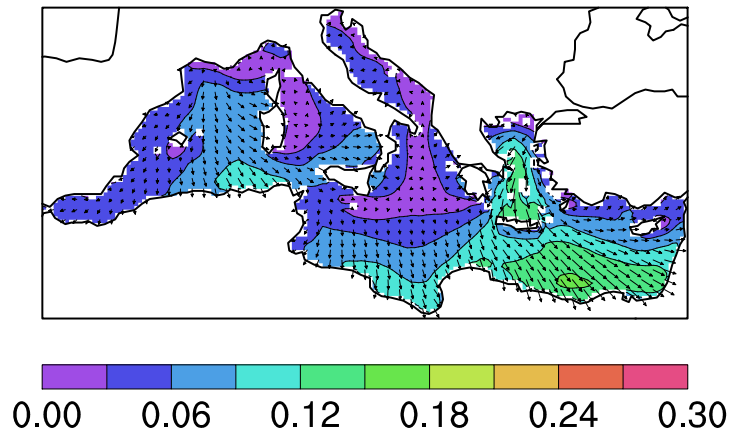

(d)

Fig. 3. Same as Fig. 2 except it shows EA/WR.

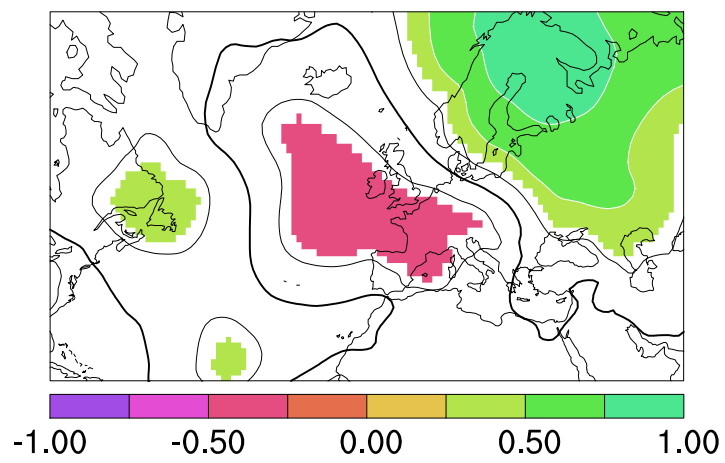

(a)
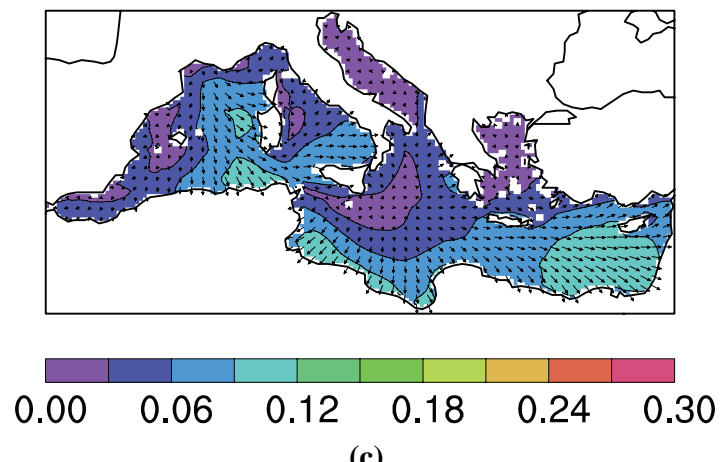

(c)
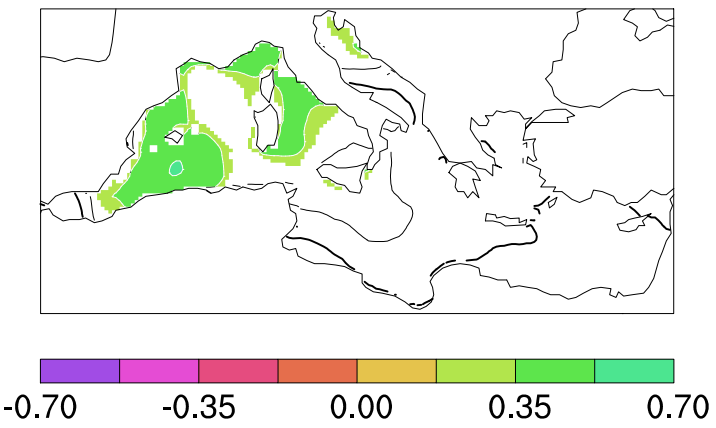

(b)
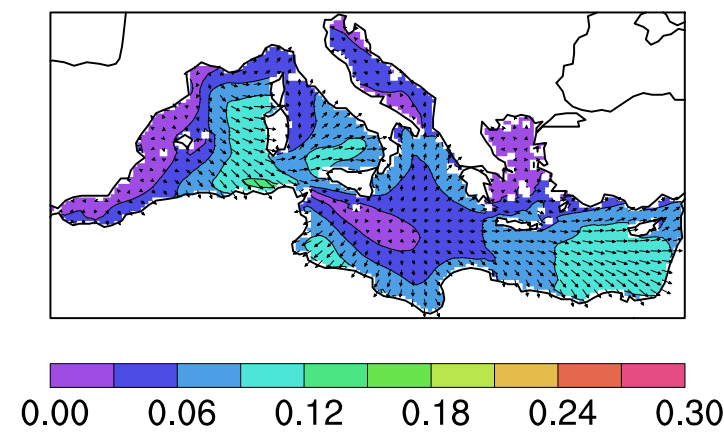

(d)

Fig. 4. Same as Fig. 2 except it shows SCA in April. 


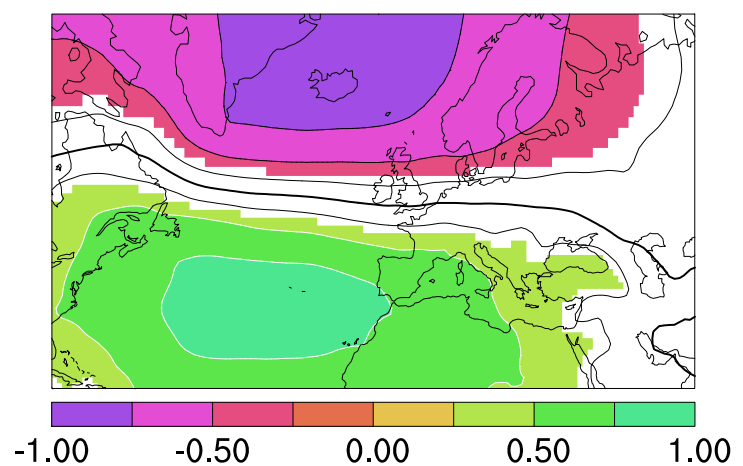

(a)
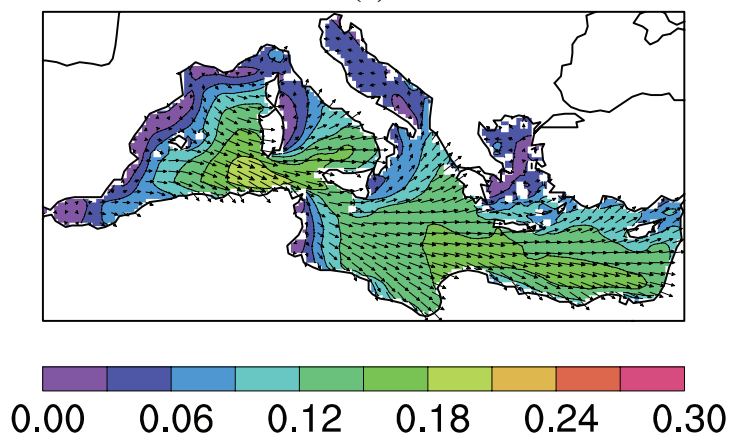

(c)

Fig. 5. Same as Fig. 2 except it shows NAO.

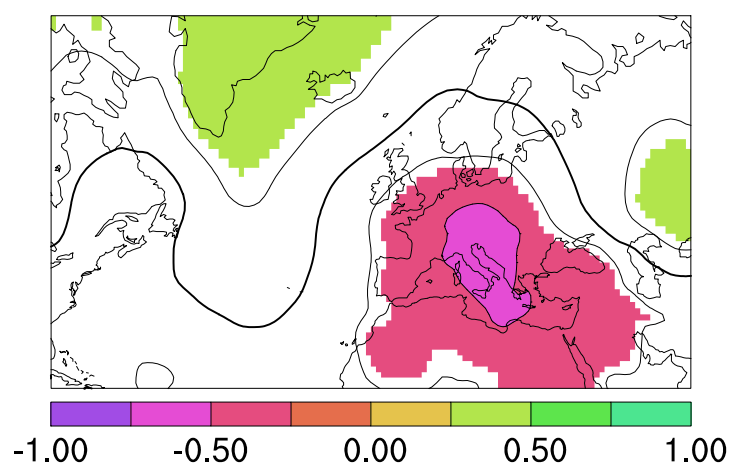

(a)
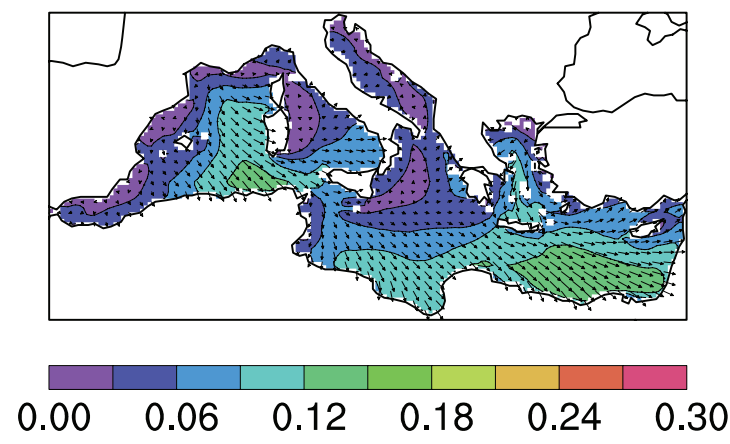

(c)
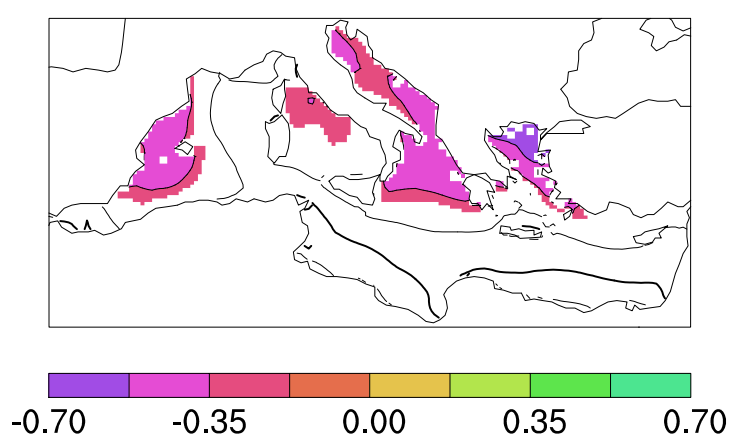

(b)
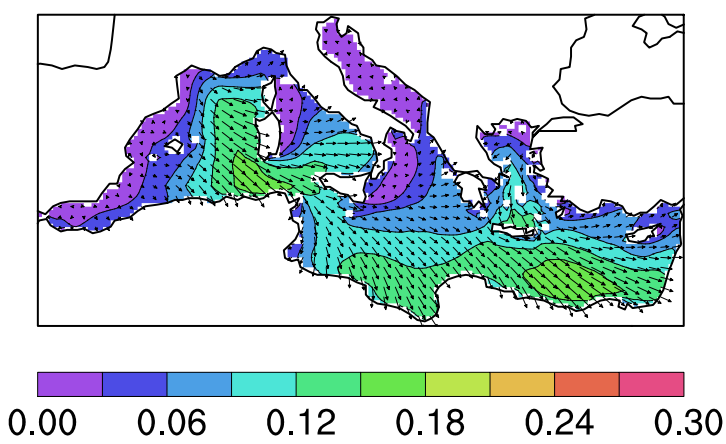

(d)
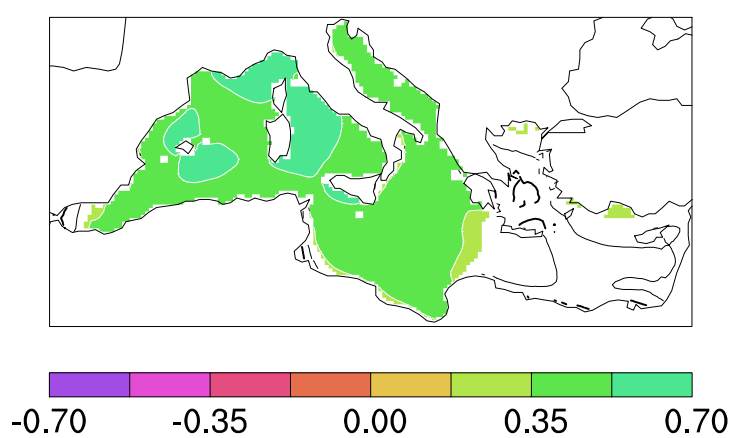

(b)
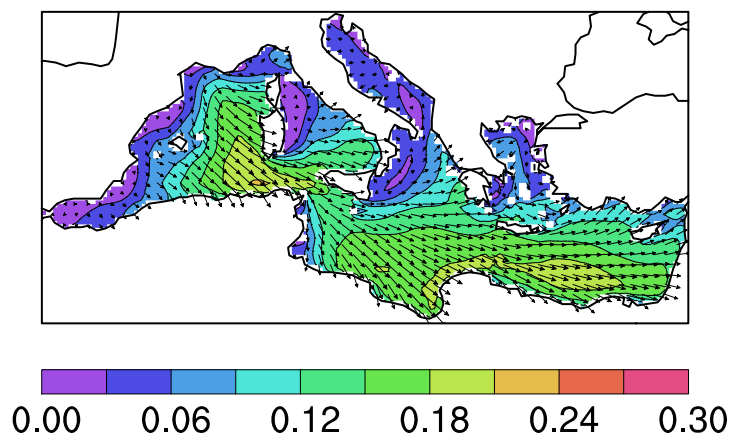

(d)

Fig. 6. Same as Fig. 2 except it shows EP/NP. 
The main result is an indication of the complexity of regional interactions, which cannot be explained by a single large scale TLC, so that several mid-latitude patterns are linked to the SWH field in the Mediterranean, especially for the cold season and the western part. NAO, which is often suggested to be the main factor for the description of climate variability in southern Europe, is not the most important TLC for the SWH field (and therefore for surface winds and atmospheric circulation) in the Mediterranean at monthly scale. Mainly the East Atlantic Pattern (EA), but also the Scandinavia Pattern (SCA), East Atlantic/West Russia Pattern (EA/WR) and even the East Pacific/North Pacific Pattern (EP/NP) have a comparable, or even larger influence with respect to NAO.

This type of analysis has a shortcoming and a potential limit, because TLC patterns are identified on the basis of characteristic features at global scale. During the annual cycle, though consistently conserving their global structure, details at regional scale can differ considerably. These details can have important effects on regional variables, such as SWH, and their presence explains the large intermonthly variability of the link between Mediterranean SWH and TLC patterns. It happens, moreover, that patterns that are very different in their global structure can be associated to similar features at regional scale and have similar influence on the regional SWH variability in the Mediterranean Sea.
Acknowledgements. For this study, M. B. Galati has been supported by the Italian Project VECTOR (VulnErability of the Italian coastal area and marine Ecosystems to Climatic changes and Their rOle in the Mediterranean caRbon cycles) funded by the Italian Ministry of Research and University (http://vector-conisma.geo.unimib.it/)

Edited by: A. Mugnai

Reviewed by: one anonymous referee

\section{References}

Barnston, A. G. and Livezey, R. E.: Classification, seasonality and persistence of low-frequency atmospheric circulation patterns, Mon. Weather Rev., 115, 1083-1126, 1987.

Lionello, P. and Sanna, A.: Mediterranean wave climate variability and its links with NAO and Indian Monsoon, Clim. Dynam., 25, 611-623, 2005.

Lionello, P., Malanotte-Rizzoli, P., Boscolo, R., Alpert, P., Artale, V., Li, L., Luterbacher, J., May, W., Trigo, R., Tsimplis, M., Ulbrich, U., and Xoplaki, E.: The Mediterranean climate: an overview of the main characteristics and issues, in: Mediterranean Climate Variability, edited by: Lionello, P., MalanotteRizzoli, P., and Boscolo, R., Amsterdam, Elsevier (Netherlands), 1-26, 2006.

Simmons, A. J. and Gibson, J. K.: The ERA-40 project plan, ERA40 project report series n.1., 2000.

WAMDI group: Hasselmann, S., Hasselmann, K., Bauer, E., Janssen, P. A. E. M., Komen, G., Bertotti, L., Lionello, P., Guillaume, A., Cardone, V. C., Greenwood, J. A., Reistad, M., Zambresky, L., and Ewing, J. A.: The WAM model - A third generation ocean wave prediction model, J. Phys. Oceanogr., 18, 1776$1810,1988$. 